\title{
TOPONÍMIA E HISTÓRIA: A GUERRA DO PARAGUAI EM NOMES DE RUAS E PRAÇA DE DOURADOS - MS
}

Marilze Tavares ${ }^{1}$

RESUMO: Neste artigo, apresentamos resultados de uma investigação que toma como objeto de estudo a microtoponímia da cidade de Dourados - MS (Brasil). Procuramos demonstrar como um importante fato histórico ocorrido no Brasil - a Guerra do Paraguai -, com importantes consequências para a região em que a cidade está localizada, deixou marcas nos nomes de ruas e de outros espaços urbanos. Para o estudo, utilizamos, fundamentalmente, os pressupostos teóricos e metodológicos de Dick (1990, 1992). A análise dos dados evidenciou que 11 (onze) topônimos, do recorte tomado para a pesquisa, estão relacionados à Guerra por meio, principalmente, de homenagem a militares que estiveram envolvidos no conflito.

Palavras-Chave: toponímia; toponímia urbana; história; Guerra do Paraguai.

\section{INTRODUÇÃO}

A nomeação é uma atividade inerente ao ser humano. Dick (1997, p. 96-97) menciona que "obras antigas da história e da civilização mundiais" apontam essa prática como rotineira, embora distinta da que podemos observar no processo denominativo moderno. A autora lembra que nos versículos iniciais de Gêneses, por exemplo, vários acidentes geográficos são citados com seus respectivos topônimos: rio Eufrates, rio Giom, rio Pisom, rio Tigre, terras de Havilá, terras de Cuxe, entre outros.

Nomeamos o que está a nossa volta por muitas razões, e quando nomeamos os espaços, o fazemos principalmente por uma questão de organização. O processo que envolve a nomeação de lugares resultou numa categoria de nomes que chamamos de topônimos e, por serem tão importantes para o homem, os topônimos tornaram-se objeto de estudo de uma ciência ligada à Línguística: a Toponímia (subdivisão da Onomástica).

A Toponímia, inicialmente, se ocupou apenas da elucidação do significado ou da etimologia de uma lista de nomes topográficos. No entanto, com o passar do tempo, se percebeu que seu alcance poderia ser muito mais abrangente e hoje há muitas possibilidades de estudo a partir dos nomes próprios de lugares sejam eles da área rural ou da área urbana. Por meio do estudo dos topônimos, é possível se proceder ao resgate de parte da história, da cultura, do modo de vida de grupos que

\footnotetext{
${ }^{1}$ Doutora em Estudos da Linguagem pela Universidade Estadual de Londrina (2015). Professora da Universidade Federal da Grande Dourados. E-mail: marilze.tavares@terra.com.br
} 
habitam ou habitaram determinados espaços. Esse seria, aliás, um dos principais focos das pesquisas toponímicas atuais.

Considerando que a escolha dos nomes de lugares, em geral, está relacionada com a história do local ou da região, neste estudo temos como objetivo verificar em que medida um importante fato histórico ocorrido no Brasil - a Guerra do Paraguai - deixou marcas nos nomes de ruas, avenidas e praças da cidade de Dourados, no estado de Mato Grosso do Sul - MS. O estudo pretende evidenciar quais foram as personalidades, os locais e os fatos relacionados à Guerra que mereceram homenagens se tornando nomes de ruas e de outros logradouros na cidade.

Antes de passarmos à apresentação dos resultados desta investigação, apresentamos os pressupostos teóricos e metodológicos da pesquisa toponímica nos quais nos pautamos, algumas considerações sobre o município de Dourados e sobre a história relacionada à Guerra do Paraguai.

\section{TOPONÍMIA E TOPONÍMIA URBANA: BREVES ASPECTOS TEÓRICOS E METODOLÓGICOS}

O filólogo Leite de Vasconcellos (1931, p. 03) conceituou Toponímia como o "estudo dos nomes de sítios, de povoações, de nações, de rios, de montes, de vales etc., - isto é, dos nomes geográficos". Já Salazar-Quijada (1985, p. 18) define Toponímia como

[...] aquella rama de la Onomástica que se ocupa del estudio integral, en el espacio y en el tiempo, de los aspectos geo-históricos, socioeconómicos y antropo-lingüísticos, que permitieron y permiten que un nombre de lugar se origine y subsista.

Como se nota, o primeiro autor refere-se apenas à toponímia de espaços "rurais", no entanto os topônimos dos espaços urbanos, como os nomes de ruas, avenidas, bairros e praças são também de interesse da Toponímia.

Como corpo disciplinar, a Toponímia surgiu na França, por volta de 1878, tendo Auguste Longnon como precursor. A partir de um curso que ministrou na École Pratique des Hautes-Études e no Colégio de França, seus alunos publicaram a obra tida como clássica para o conhecimento da nomenclatura dos lugares habitados: Les noms de lieu de la France (1912) (DICK, 1992, p. 01). Desde o seu surgimento, essa ciência se ampliou muito e hoje há estudos significativos sobre nomes de lugares em várias partes do mundo.

A história dos nomes de lugares, em qualquer espaço físico considerado, apresenta-se como um repositório dos mais ricos e sugestivos, face à complexidade dos fatores envolventes (DICK, 1990, p.19). A partir de estudos toponímicos, evidencia-se, por exemplo, a panorâmica regional em seus aspectos naturais ou antropoculturais, a depender dos recortes e intenções do pesquisador. É nesse sentido que a autora afirma que os topônimos são

[...] verdadeiros testemunhos históricos de fatos e ocorrências registrados nos mais diversos momentos da vida de uma população, encerram em si, um valor que transcende ao próprio ato da nomeação: se a Toponímia situa-se como a crônica de um povo, gravando o presente para o conhecimento das gerações futuras, 0 
topônimo é o instrumento dessa projeção temporal (DICK, 1990, p.23)

Quando investigamos aspectos da toponímia urbana, verificamos com mais recorrência, fatores antropoculturais como motivadores da denominação, ou seja, nomes de pessoas, nomes de outros locais, datas de acontecimentos históricos entre outros aparecem na designação das ruas, das avenidas e praças de qualquer cidade. Já na toponímia rural, aspectos de natureza física como nomes relacionados à vegetação, aos animais, aos recursos hídricos aparecem entre os mais recorrentes. Entretanto, independentemente do recorte que se toma para um estudo toponímico, é preciso considerar que

[...] a toponímia é a disciplina que caminha ao lado da história, servindo-se de seus dados para dar legitimidade a topônimos de um determinado contexto regional, inteirando-se de sua origem para estabelecer as causas motivadoras, num espaço de tempo preciso, procurando relacionar um nome ao outro [...]. (DICK, 1996, p.12).

Nesse sentido, este trabalho é também um exercício de fazer a relação entre os topônimos urbanos de Dourados vinculados à Guerra do Paraguai. Por essa razão, as informações enciclopédicas (ver Quadro 02) levantadas, sintetizadas e apresentadas sobre cada um dos nomes analisados se constitui como a maior contribuição desta pesquisa.

Ainda sobre a situação das pesquisas toponímicas atuais, é preciso registrar que, no Brasil, existem muitos projetos, em algumas universidades, que têm como foco o estudo de nomes de acidentes geográficos. Para ficarmos com alguns exemplos, citamos o maior, ATB, Atlas Toponímico do Brasil (USP); o ATEMIG, Atlas Toponímico de Minas Gerais (UFMG); ATEMS, Atlas Toponímico do Estado de Mato Grosso do Sul (UFMS); o ATEPAR, Atlas Toponímico do Paraná (UEL); ATEMT, Atlas Toponímico do Mato Grosso (UFMT); entre outros. Nesses projetos, o foco principal tem sido o estudo dos topônimos relativos aos acidentes geográficos físicos e os relativos aos nomes de cidades, distritos e pequenas localidades. Os trabalhos relativos aos nomes de ruas, avenidas, praças, e outras localidades da área urbana ainda são poucos em relação aos demais. Esse tipo de topônimo, entretanto, da mesma forma que os demais permitem diversas possibilidades de enfoque quando se desejam recuperar e compreender características de uma região, sobretudo aquelas relacionadas à história e à cultura das pessoas que ali vivem ou viveram.

Os designativos urbanos com quais trabalhamos nesta investigação também costumam ser chamados de hodônimos (do grego hodós: caminho, via; e ónoma: lugar). Houaiss (2001) confirma: hodônimo é o "[...] designativo de logradouro, rua, estrada, praça, largo e afins".

Mori (2007), ao apresentar estudo sobre a toponímia de Buenos Aires (Argentina), explica que as designações urbanas identificam e traduzem um referente urbano como uma rua, uma passagem, uma avenida, uma praça, entre outros de modo preciso para permitir uma fácil orientação no espaço urbano. Como já afirmamos, todos precisamos dos nomes, sobretudo dos nomes próprios, para nos organizarmos no meio em que vivemos. Contudo, os designativos urbanos, ao mesmo tempo, constituem um meio oficial para homenagear pessoas que têm contribuído com seus feitos, obras e doações para o engrandecimento da cidade, do 
país ou ao progresso universal. Convém registrar que não é nosso objetivo avaliar se os feitos, as obras e as doações são realmente dignos de homenagens.

Mori também afirma que, sua grande continuidade e disponibilidade no discurso, os nomes de ruas, em especial, se prestam para investigações que relacionam o aspecto histórico e o cultural. Além de terem função orientadora, servem como transmissores da memória cultural da cidade e têm caráter de monumento, recordando não apenas o positivo, mas o oprimido e o esquecido também (MORI, 2007, p.316).

Outra questão a considerar, quando se investigam as designações urbanas, é que os signos toponímicos não são empregados em sua função primária, ou seja, são segundas designações ${ }^{2}$ (MORI, 2007, p.318). Em outras palavras, Guimarães $(2002,47)$ também menciona essa característica dos hodônimos:

[...] a unidade do nome de rua não é construída pela enunciação que nomeia a rua, mas por outra enunciação que está contida na enunciação que nomeia a rua.

A enunciação dos nomes de ruas é sempre uma enunciação a partir de outra enunciação.

No caso de ruas com nomes próprios de pessoa, a enunciação que nomeia a rua toma e inclui a nomeação que nomeou a pessoa.

Além disso, os nomes próprios, sobretudo de pessoa, quando empregados em função toponímica podem sofrer modificações em sua estrutura. A redução de elementos da composição dos nomes é o procedimento mais comum e isso ocorre para que esses signos cumpram de forma mais precisa sua nova função. Reduzidos, eles se tornam mais fáceis de serem memorizados (MORI, 2007, p. 318). Assim a praça central e mais conhecida de Dourados recebeu o nome de Praça Antônio João, em homenagem a Antônio João Ribeiro, como mostraremos mais adiante.

Como já mencionado, os nomes de pessoas constituem, em geral, o principal campo semântico de onde procedem as designações de ruas e praças. As principais ruas e avenidas de Dourados têm nomes e sobrenomes de pessoas: Avenida Marcelino Pires, Avenida Weimar Torres, Rua Joaquim Teixeira Alves, Rua Oliveira Marques. Esses antropônimos (nomes de pessoas) podem aparecer também acompanhados de uma titulação (ou outro determinante), como, por exemplo, Rua Major Capilé, Rua General Câmara, Rua Doutor Camilo Ermelindo da Silva.

Os nomes de ruas, entretanto, podem ser originários de outros campos semânticos, alguns menos e outros mais recorrentes, como os que seguem: nomes próprios topográficos: Rua Alto da Boa Vista; nomes próprios de cidade, estado ou país: Rua Cuiabá, Rua Mato Grosso, Rua Alemanha; nomes de fatos históricos: Rua da Abolição, Rua 07 de Setembro, Rua 20 de Dezembro (aniversário de Dourados); nomes de animais e de plantas: Rua Arara Azul, Rua dos Beija-flores, Rua das Dálias, Rua dos Pessegueiros.

Registramos que para as pesquisas toponímicas, no âmbito do Projeto ATEMS, cuja equipe integramos como pesquisadora, os dados são coletados prioritariamente dos mapas do Instituto Brasileiro de Geografia e Estatística da escala 1:100.000 (1987), que são disponibilizados no site do Instituto. Não há,

\footnotetext{
${ }^{2}$ Entendemos que outros topônimos vinculados a elementos da área rural, frequentemente, também não são, como designativos geográficos, nomes de primeira enunciação, ou seja, antes de serem nomes de córregos, morros, rios já são nomes de animais, de plantas ou de outros elementos da natureza ou não. Essa não é, entretanto, uma discussão que precisa ser aprofundada neste trabalho.
} 
porém, disponíveis mapas do IBGE em que apareçam os topônimos urbanos nas condições em que necessitamos para as pesquisas. Por essa razão, os dados analisados neste estudo foram coletados de um mapa da área urbana da cidade encontrado em bancas de revistas e livrarias (organizado/patrocinado por empresas particulares e atualizado em 2016) e, posteriormente conferidos a partir de um programa disponível no site da Prefeitura de Dourados ${ }^{3}$.

\section{A CIDADE DE DOURADOS: BREVES INFORMAÇÕES CONTEXTUAIS}

O município que conhecemos como Dourados teve origem em um povoado chamado São João Batista de Dourados, topônimo relacionado à proximidade com o Rio Dourados - o nome do rio teria sido motivado pela intensa presença de peixe da espécie dourado. O povoado se tornou município em 20 de dezembro 1935.

Atualmente Dourados é o segundo maior município de seu estado e se localiza no Conesul de Mato Grosso do Sul; situa-se a aproximadamente 220 quilômetros da capital, Campo Grande. Seus limites são os seguintes: ao Norte: com Rio Brilhante, Maracaju, Douradina e Itaporã; ao Sul: Fátima do Sul, Caarapó, Laguna Carapã e Ponta Porã; ao Leste: com Deodápolis; e a Oeste, com o município de Ponta Porã. Convém mencionar que Dourados está a aproximadamente 120 quilômetros da fronteira seca com o país vizinho, Paraguai.

De acordo com informações do site do IBGE, o Censo (2010) contabilizou uma população de 196.035 no município; já em 2014, a estimativa era que a população estivesse em 210.218, vivendo em uma área de unidade territorial de 4.086. $237 \mathrm{~km}^{4}$.

\section{A GUERRA DO PARAGUAI: SÍNTESE DE DUAS VERSÕES}

A Guerra do Paraguai, que também é chamada Guerra da Tríplice Aliança na Argentina e no Uruguai, e de Guerra Grande no Paraguai, foi o maior conflito armado internacional ocorrido na América do Sul no século XIX. O confronto durou seis anos - de dezembro de 1864 a 1870 - sendo encerrado com a morte de Francisco Solano López em Cerro Cora e com a vitória da Tríplice Aliança sobre o Paraguai.

Quando realizamos pesquisas sobre o que se tem registrado a respeito dos motivos pelos quais a Guerra teria começado, é comum encontrarmos duas versões. A primeira e, ao que parece, a mais aceita pelos historiadores especialistas no assunto, estaria associada ao fato de que o Paraguai foi um dos países que pretendiam a independência política na América Latina. Tendo construído essa independência ao longo de um tempo, em 1811, já poderia dispensar o capital estrangeiro.

Nessa época, a potência mundial era a Grã-Bretanha a quem não interessava um país como o Paraguai que começava a se isolar e não mantinha dívidas com nenhum outro. Já o Brasil e a Argentina, vizinhos do Paraguai e dois dos maiores países da América Latina, estavam incorporados ao sistema mundial, que envolvia o

3 Geo Dourados Banco de Dados Multifinalitário. Disponível em http://geo2.dourados.ms.gov.br/geodourados/map.phtml. Acesso em 20 de junho de 2017.

${ }^{4}$ INSTITUTO BRASILEIRO DE GEOGRAFIA E ESTATÍSTICA - IBGE. Censo 2010. Disponível em www.censo2010.ibge.gov.br/ Acesso em 03/12/2016. 
imperialismo inglês. O desejo que o Paraguai tinha de não se subordinar e se manter independente financeiramente teria provocado o descontentamento da Inglaterra. Esse fator somado aos projetos expansionistas dos países vizinhos do Paraguai teriam sido os desencadeadores do início da Guerra.

Outra versão sobre os fatos que motivaram a Guerra é a que relata que Francisco Solano López, governante paraguaio, teria iniciado o conflito devido à necessidade e intenção de tomar territórios dos vizinhos. Ou seja, nessa versão quem desejava primeiro expandir as fronteiras era o Paraguai. Além disso, Solano López pretendia liberar uma saída para o Oceano Atlântico através dos rios da bacia do rio Prata.

Nessa versão, em 11 de novembro de 1864, o navio brasileiro Marquês de Olinda foi aprisionado no Rio Paraguai por uma embarcação armada paraguaia. $O$ fato teria provocado o rompimento das relações entre os países e, em dezembro do mesmo ano, a Guerra começou com uma ofensiva de Solano López ao Mato Grosso brasileiro. Argentina e Uruguai teriam sido provocados também e por essa razão os três países procederam a uma aliança para contra-atacar o Paraguai.

Dessa forma, o "ditador" paraguaio teria sido o responsável pelo início do conflito que destruiu a economia e a população de seu próprio país.

O fato é que antes da Guerra, o Paraguai era uma potência econômica na América do Sul e, após o confronto, nunca mais voltou a ser um país com bom índice de desenvolvimento econômico. Os registros históricos mostram que o confronto foi um grande massacre, e, para muitos estudiosos do assunto, uma verdadeira covardia contra o Paraguai. O conflito é, inclusive, chamado também de Guerra contra o Paraguai (em oposição ao nome oficial Guerra do Paraguai).

Apesar disso, para muitas pessoas, formadas pelas versões de livros didáticos utilizados nas escolas de Educação Básica, o Brasil demonstrou coragem, força, e resistência na defesa de seu povo e de seu território. Muitos combatentes são considerados heróis e são dignos de honrarias e homenagens. Legitima essa visão o discurso produzido por escritores chamados de memorialistas ligados a uma elite que detém o poder e tem interesse em criar uma identidade histórica que reforça interesses próprios.

Nesse sentido, datas, episódios e personagens relacionados à Guerra são rememorados, por exemplo, em topônimos de várias cidades brasileiras, sobretudo no Mato Grosso do Sul.

A historiadora Squinelo (2015) dedicou um capítulo da sua obra, A Guerra do Paraguai ontem e hoje - Mato Grosso e Mato Grosso do Sul (1868-2003), à questão da nomeação de espaços urbanos como designativos que rememoram a Guerra.

Conforme esclarece a autora, não foi seu objetivo fazer o estudo dos nomes de todas as ruas e avenidas dos municípios de Mato Grosso do Sul. Por isso, para desenvolver essa parte de sua pesquisa, utiliza "[...] um conjunto de ruas situadas no bairro São Francisco, em Campo Grande - MS e outras dispersas pelo centro da cidade, que homenageiam as batalhas e personagens da Guerra do Paraguai" (SQUINELO, 2015, p. 143). A respeito de outros municípios, Squinelo apenas cita alguns topônimos que estariam relacionados à Guerra.

$\mathrm{Na}$ sequência apresentamos os topônimos cujas informações enciclopédicas levantadas mostram que estão, de alguma forma, fazendo referência ao fato histórico em questão.

\section{ANÁLISE DAS DESIGNAÇÕES URBANAS ASSOCIADAS À GUERRA}


Após a observação de mais de 840 nomes (de acordo com o mapa-fonte utilizado para este estudo) de ruas e dos nomes de sete praças ${ }^{5}$ da área urbana de Dourados, verificamos 11 referências a personalidades e locais associados à Guerra do Paraguai.

De modo geral, as pesquisas toponímicas costumam apresentar um conjunto de nomes geográficos analisados conforme sua motivação, sua estrutura morfológica e sua língua de origem. Informações enciclopédicas sobre os nomes são apresentadas, principalmente, para ajudar a confirmar as classificações realizadas pelo pesquisador. Neste estudo, no entanto, consideramos relevante para o alcance dos objetivos a elucidação da motivação e as informações enciclopédicas uma vez que são elas que nos permitem correlacionar um nome ao outro no contexto do conflito.

No Quadro 01 apresentamos os sintagmas toponímicos (divididos em elemento genérico e elemento específico) seguidos da classificação de sua motivação, conforme modelo teórico utilizado.

Quadro 01 - Sintagmas toponímicos e motivação

\begin{tabular}{|l|l|c|}
\hline \multicolumn{2}{|c|}{ Sintagma toponímico } & $\begin{array}{c}\text { Taxionomia } \\
\text { (motivação) (Dick, } \\
\text { 1990/1992) }\end{array}$ \\
\hline genérico & \multicolumn{1}{|c|}{ específico } & hidrotopônimo \\
\hline Rua & Aquidabã & antropotopônimo \\
\hline Rua & Benjamin Constant & axiotopônimo \\
\hline Rua & Fuque de Caxias & antropotopônimo \\
\hline Rua & General Câmara & axiotopônimo \\
\hline Rua & General Osório & axiotopônimo \\
\hline Rua & Guia Lopes & axiotopônimo \\
\hline Rua & Humaitá & corotopônimo \\
\hline Rua & Riachuelo & hidrotopônimo \\
\hline Rua & Visconde de Taunay & axiotopônimo \\
\hline Praça & Antônio João & antropotopônimo \\
\hline
\end{tabular}

Fonte: a própria autora

Como é possível observar no Quadro 01, cinco dos onze topônimos analisados são nomes individuais de pessoas seguidos de título, função ou cargo: Rua Duque de Caxias, Rua General Câmara, Rua General Osório, Rua Guia Lopes,

\footnotetext{
${ }^{5}$ Os nomes das praças são os seguintes: Praça Antônio João, Praça Mário Correia, Praça do Cinquentenário, Praça Paraguaia, Praça Rui Gomes, Praça Pedro Rigotti, Praça Filinto Muller e Praça do Centenário da Imigração Japonesa.
} 
Rua Visconde de Taunay. Topônimos dessa natureza são classificados por Dick (1990, 1992) como axiotopônimos. Verificamos também que dois são nomes de pessoas, sem indicação de título, cargo ou função: Rua Floriano Peixoto e Praça Antônio João Ribeiro, portanto, antropotopônimos; outros dois são nomes de rios Rua Aquidabã e Rua Riachuelo - e por isso são classificados de hidrotopônimos, que são aqueles resultantes de acidentes hidrográficos; um dos designativos foi classificado como corotopônimo, que é a categoria em que Dick encaixa topônimos que já são nomes de outras localidades - Rua Humaitá (Humaitá é nome de uma região do Paraguai, conforme podemos verificar pelas informações do Quadro 02).

É preciso esclarecer que classificar os nomes dessa forma, em várias categorias, foi uma opção para este estudo, uma vez que, quando tomamos as diversas taxes do modelo de Dick $(1990,1992)$, todos esses designativos poderiam ser incluídos na categoria dos historiotopônimos, que são os "[...] topônimos relativos aos movimentos de cunho histórico-social e aos seus membros, assim como as datas correspondentes" (DICK, 1990, p.33). Como se constata, a definição da categoria dos historiotopônimos é, conforme a autora, abrangente.

Observando a mesma questão, Sartori (2010), ao realizar estudo sobre nomes de ruas de Caxias do Sul, opta por duas classificações para alguns dos nomes analisados. Como a autora prefere referir-se aos nomes de ruas por "hodônimos" (como outros pesquisadores também o fazem), classifica Avenida Júlio de Castilho e Rua Bento Gonçalves como "antropo-hodônimo" e também como "historio-hodônimo".

Vale mencionar ainda que apenas dois dos nomes analisados nesta pesquisa têm motivação relacionada a aspectos de natureza física: Rua Aquidabã e Rua Riachuelo, que são nomes de rios que passaram a nomes de ruas. Por essa razão, estão classificados, no Quadro 02, como hidrotopônimos. Os demais desigantivos têm motivação baseada em aspectos de natureza antropocultural.

$\mathrm{Na}$ sequência, estão as informações enciclopédicas - entendidas aqui como as informações gerais, e não apenas as propriamente linguísticas dos nomes. Para elaboração do Quadro 02, valemo-nos principalmente de resultados de pesquisa realizada por Gressler (1996) que foram por nós resumidos.

Quadro 02 - Informações enciclopédicas sobre os topônimos

\begin{tabular}{|l|l|}
\hline $\begin{array}{c}\text { Sintagma } \\
\text { toponímico }\end{array}$ & \multicolumn{1}{c|}{ Informação enciclopédica } \\
\hline $\begin{array}{l}\text { Rua } \\
\text { Aquidabã }\end{array}$ & $\begin{array}{l}\text { O nome Aquidabã é uma homenagem à vitória do Brasil na Guerra do } \\
\text { Paraguai, na Batalha de Riachuelo que se realizou às margens do Rio } \\
\text { Aquidabã entre o Paraguai e o Mato Grosso. Nesse rio aconteceu a } \\
\text { última grande batalha entre os guerrilheiros, em 1870. (GRESSLER, } \\
\text { 1996, p. 36-37). }\end{array}$ \\
\hline $\begin{array}{l}\text { Rua } \\
\text { Benjamin }\end{array}$ & $\begin{array}{l}\text { Benjamin Constant Botelho de Magalhaes (1836 - 1891). Nasceu no } \\
\text { Rio de Janeiro e aos 15 anos ingressou na Escola Militar, fazendo } \\
\text { carreira no Exército. Bacharelou-se em Ciências Físicas e } \\
\text { Matemáticas. Tornando-se capitão, recebeu ordem para tomar parte } \\
\text { na Guerra do Paraguai. (GRESSLER, 1996, p. 48). }\end{array}$ \\
\hline $\begin{array}{l}\text { Rua Duque } \\
\text { de Caxias }\end{array}$ & $\begin{array}{l}\text { Duque de Caxias foi como ficou mais conhecido Luís Alves de Lima e } \\
\text { Silva (1803-1880). Nascido na então província do Rio de Janeiro, } \\
\text { recebeu os títulos de barão, conde, marquês e, finalmente, duque de }\end{array}$ \\
\hline
\end{tabular}




\begin{tabular}{|c|c|}
\hline & $\begin{array}{l}\text { Caxias. Entre } 1818 \text { a } 1821 \text { cursou a Academia Real Militar. Saiu deste } \\
\text { estabelecimento como tenente e, no exército, chegou a marechal. Em } \\
1866 \text { foi chamado a assumir o comando das forças brasileiras na } \\
\text { Guerra do Paraguai. Foi proclamado, por decreto em 1962, "Patrono } \\
\text { do Exército Brasileiro". (GRESSLER, 1996, p. } 70-71 \text { ) }\end{array}$ \\
\hline $\begin{array}{l}\text { Rua Floriano } \\
\text { Peixoto }\end{array}$ & $\begin{array}{l}\text { Floriano Vieira Peixoto }(1839-1895) \text { nasceu em Maceió (AL). } \\
\text { Ingressou na Escola Militar e deu início a uma "gloriosa" carreira no } \\
\text { Exército. Foi designado para comandar um batalhão de infantaria em } \\
\text { Bagé (RS). Participou da Guerra do Paraguai comandando uma } \\
\text { esquadra de navios e, posteriormente, um batalhão de voluntários e foi } \\
\text { honrado com vários títulos e medalhas. Em } 1890 \text { foi promovido a } \\
\text { Marechal-de-Exército e, em 1891, elegeu-se vice-presidente da } \\
\text { república; assumiu a presidência devido à renúncia de Deodoro da } \\
\text { Fonseca. (GRESSLER, 1996, p. 125). }\end{array}$ \\
\hline $\begin{array}{l}\text { Rua General } \\
\text { Câmara }\end{array}$ & $\begin{array}{l}\text { General Câmara - José Antônio Corrêa da Câmara (1824-1893) - } \\
\text { nasceu em Porto Alegre, província do Rio Grande do Sul. Em 1839 } \\
\text { entrou como voluntário para o 3ํRegimento de Cavalaria Ligeira, indo } \\
\text { combater os revolucionários "farroupilhas". Foi capitão, major, tenente- } \\
\text { coronel, marechal de campo, general e marechal do exército. Tomou } \\
\text { parte no assalto a Paissandu em } 02 \text { de janeiro de 1865. No desenrolar } \\
\text { da Guerra do Paraguai, Câmara lutou nas batalhas de Tuiuti, Curupaiti, } \\
\text { Tulu-Cuê, Passo Pocu e Espinilho. (GRESSLER, 1996, p. 83-84). }\end{array}$ \\
\hline $\begin{array}{l}\text { Rua General } \\
\text { Osório }\end{array}$ & $\begin{array}{l}\text { General Osório - Manoel Luis Osório (1808-1879) - nasceu em Santo } \\
\text { Antônio do Arroio (RS), hoje município de Osório. Antes dos } 15 \text { anos } \\
\text { entrou para a Cavalaria da Legião de São Paulo e se incorporou } \\
\text { imediatamente às forças encarregadas de lutar contra portugueses } \\
\text { rebeldes a nossa independência. Em 1864, destacou-se lutando contra } \\
\text { as forças de Aguirre, quando as tropas brasileiras invadiram o Uruguai } \\
\text { e entraram em Montevidéu (Tomada de Paissandu). Mas foi na Guerra } \\
\text { do Paraguai que "a bravura e a liderança" se fizeram sentir mais do } \\
\text { que nunca. Comandando tropas em diversos combates, conseguiu } \\
\text { decisivas vitórias. (GRESSLER, 1996, p. 85-86) }\end{array}$ \\
\hline $\begin{array}{l}\text { Rua Guia } \\
\text { Lopes }\end{array}$ & $\begin{array}{l}\text { Guia Lopes - José Francisco Lopes (1811-1867) - nasceu em Piauí } \\
\text { (MG). Foi sertanista, soldado e guia das expedições de Mato Grosso. } \\
\text { Serviu de guia ao coronel Carlos de Moraes Camisão, comandante da } \\
\text { coluna expedicionária brasileira que invadiu o território paraguaio e } \\
\text { depois realizou a Retirada da Laguna (1867). (GRESSLER, 1996, p. } \\
\text { 89) }\end{array}$ \\
\hline Rua Humaitá & $\begin{array}{l}\text { Humaitá é a região do Paraguai onde se deu a Batalha de Humaitá, } \\
\text { combate travado entre brasileiros e paraguaios em } 19 \text { de fevereiro de } \\
1868 \text {, com vitória dos brasileiros. A esquadra brasileira forçou a } \\
\text { passagem de Humaitá, forte paraguaio, que foi o principal centro de } \\
\text { resistência até } 1868 \text {. Mas essa fortaleza foi rompida com o comando } \\
\text { do capitão-de-mar-e-guerra, Delfin Carlos de Carvalho. (GRESSLER, } \\
\text { 1996, p. 92-93) }\end{array}$ \\
\hline $\begin{array}{l}\text { Rua } \\
\text { Riachuelo }\end{array}$ & $\begin{array}{l}\text { Riachuelo é uma referência à batalha naval da primeira fase da Guerra } \\
\text { do Paraguai travada entre as esquadras brasileiras e paraguaias, em } \\
11 \text { de junho de } 1865 \text {, em águas do Rio Paraná, nas proximidades do } \\
\text { Rio Riachuelo. A batalha iniciou-se quando as forças navais de Solano }\end{array}$ \\
\hline
\end{tabular}




\begin{tabular}{|l|l|}
\hline & $\begin{array}{l}\text { Lopez, descendo da fortaleza paraguaia de Humaitá, pelo Rio } \\
\text { Paraguai, tentaram surpreender os navios brasileiros. Embora } \\
\text { apanhados de surpresa, os brasileiros obtiveram a vitória que tirou } \\
\text { definitivamente dos paraguaios o domínio naval da bacia do Prata. } \\
\text { (GRESSLER, 1996, p.154) }\end{array}$ \\
\hline $\begin{array}{l}\text { Rua } \\
\text { Visconde de }\end{array}$ & $\begin{array}{l}\text { Visconde de Taunay - Alfredo Maria Adriano D'Escragnolle Taunay } \\
\text { (1843-1899) nasceu no Rio de Janeiro. Em 1865 integrou a coluna que } \\
\text { seguiu para o Mato Grosso, na Guerra do Paraguai, e tomou parte da } \\
\text { operação militar que imortalizou com o seu livro A retirada da Laguna } \\
\text { (1891). Interessou pela política (tornando-se deputado e senador); } \\
\text { também pela música, pela pintura e pela literatura. Ficou muito } \\
\text { conhecido pela autoria do romance Inocência (1872). (GRESSLER, } \\
\text { 1996, p. 176 -177) }\end{array}$ \\
\hline $\begin{array}{l}\text { Praça } \\
\text { Antônio João }\end{array}$ & $\begin{array}{l}\text { Antônio João Ribeiro (1823 - 1864) nasceu em Vila de Poconé (MT). } \\
\text { Aos 17 anos assentou praça no 120 Batalhão de Caçadores de Cuiabá. } \\
\text { Foi promovido a cabo em 1841 e chegou a tenente em 1860. Prestou } \\
\text { 20 anos de serviço ao estado de mato Grosso e sua última missão foi } \\
\text { a de comandante da Colônia Militar de Dourados. (GRESSLER, 1996, } \\
\text { p. 212 - 213) }\end{array}$ \\
\hline
\end{tabular}

Fonte: a própria autora

Reiteramos que o objetivo principal do trabalho é mostrar os topônimos urbanos relacionados à Guerra. Nesse sentido, entendemos que as informações registradas por Gressler (1996) foram úteis para esta pesquisa, principalmente por já estarem compiladas em sua obra. Entretanto, é preciso ressaltar que a autora não é historiadora de formação e, talvez por isso, registra a história como a maioria das pessoas está acostumada a ler ou a ouvir, sem nenhum posicionamento crítico.

Mantivemos no resumo das informações do Quadro 02 expressões como " vitória do Brasil", "chegou a marechal", "gloriosa carreira", "a bravura e a liderança", "embora apanhados de surpresa", que contribuem para a construção dos personagens brasileiros envolvidos na Guerra como verdadeiros e destemidos heróis. Convém lembrar, no entanto, que essa é apenas uma visão ou um lado da história.

A título de curiosidade, registramos que, considerando que a Guerra do Paraguai é um dos mais importantes acontecimentos da história do Brasil, e que existe um ranking dos 100 nomes de ruas mais utilizados no Brasil $^{6}$, verificamos que o topônimo Rua Duque de Caxias figura nesse ranking e teria 329 ocorrências pelo Brasil. Os demais topônimos do corpus não aparecem no ranking, mas por meio de uma pesquisa simples de busca pela internet, é possível verificar que também têm ocorrência difundida nacionalmente, isto é, aparecem em várias cidades.

No que se refere à ocorrência dos topônimos no estado, Squinelo (2015, p. 144 - 148), menciona exemplos de cidades sul-mato-grossenses, além de Dourados, que preservam a memória do conflito por meio da nomeação de suas ruas, avenida, praças e outros monumentos: Aquidauana, Bela Vista, Campo Grande, Corumbá, Coxim, Guia Lopes da Laguna, Jardim, Miranda, Nioaque, Ponta Porã.

6 Nomes de ruas mais comuns no Brasil. Disponível em
http://www.rankbrasil.com.br/Recordes/Materias/OWQr/Nome De Rua Mais Comum No Brasil. Acesso em 23 de fevereiro de 2017. 
De acordo com o levantamento da autora, Antônio João, Guia Lopes e Alfredo d'Escragnolle Taunay são os nomes mais recorrentes na toponímia sul-matogrossense relacionada à Guerra. Os dois primeiros são tidos como os dois maiores heróis do estado e o terceiro foi/é o escritor que mais influenciou (influencia) a escrita da história sul-mato-grossense, principalmente as cunho memorialistas (SQUINELO, 2015, p. 149).

Dos designativos analisados nesta pesquisa, o mais enunciado em Dourados é Antônio João por ser nome da principal praça da cidade. A praça fica no centro, está integrada ao pátio da Catedral Nossa Senhora da Conceição e é ponto de referência para o comércio, os bancos e outros estabelecimentos do seu entorno.

\section{CONSIDERAÇÕES FINAIS}

Os topônimos, em geral, são bem mais que designativos de orientação e de especificação dos elementos que se referem. Eles registram aspectos de um passado mais recente ou mais remoto, e, especialmente nos topônimos de elementos urbanos, é possível encontrar homenagens a pessoas que são tidas como ilustres e importantes por algum de seus feitos. Dependendo dos objetivos do pesquisador, olhando-se com atenção para esses nomes, também é possível verificar quais ideologias prevalecem na nomeação do espaço.

É possível que a maioria da população douradense, com exceção daquelas pessoas que trabalhem ou que tenham muito interesse por história, não relacione alguns dos nomes aqui analisados com o fato histórico ao qual estão associados. Ou seja, nomes que remetem a pessoas e locais considerados importantes para a história da região e do país, são pronunciados, no cotidiano, apenas como simples referentes de localização.

Isso é natural uma vez que o signo toponímico pode apresentar algumas características como o esvaziamento do significado que chega a levar a sua opacidade. Em outras palavras, se não conhecemos a história ou estamos muito distante do momento da nomeação, não saberemos ou não nos lembraremos mais da motivação dos designativos geográficos.

A quantidade de topônimos associados à Guerra encontrada na toponímia urbana de Dourados não parece significativa em um primeiro momento: foram apenas onze em um universo de mais de 800 nomes. O olhar mais atento para esses nomes, entretanto, permite a quem se debruçar sobre eles conhecer muito da história da região. Esse é um dos principais pressupostos dos estudos toponímicos.

Um trabalho possível, que poderia completar as conclusões deste breve estudo, seria uma pesquisa que evidenciasse em que medida cidades do lado paraguaio conservam marcas da Guerra em sua toponímia urbana, destacando, entre outras questões, quais os personagens e os fatos que mereceram homenagem tornando-se topônimos naquele país.

\section{Abstract}

In this paper we present results of an investigation that takes as object of study the microtoponyms of the city of Dourados - MS (Brazil). We tried to demonstrate how an important historical fact occurred in Brazil, - War of Paraguay -, with important consequences for the region where the city is located, it left marks in the names of streets and other urban spaces. For the study, we use, fundamentally, the theoretical and methodological assumptions of Dick (1990, 1992). The analysis of the data 
showed that 11 (eleven) toponyms, of the cut taken for the research, are related to the War through, mainly, homage to the military that were involved in the conflict.

Keywords: toponymy; urban toponymy; history; War of Paraguay

\section{REFERÊNCIAS}

DICK, Maria Vicentina do Amaral. A motivação toponímica e a realidade brasileira. São Paulo: Edições Arquivo do Estado de São Paulo, 1990.

A Dinâmica dos nomes na cidade de São Paulo 1554-1897. São Paulo: ANABLUME, 1996.

. Toponímia e cultura. In: Revista do Instituto de Estudos Brasileiros. São Paulo, 1987. P. 93-101.

GRESLLER, Lori Alice. Memórias de Dourados: ruas, edifícios e logradouros públicos. Prefeitura Municipal de Dourados/MS. Dourados: 1996.

GUIMARÃES, Eduardo. Semântica do acontecimento. São Paulo: Pontes, 2002.

HOUAISS, Antônio; VILLAR, Mário Sales. Dicionário eletrônico Houaiss da língua portuguesa. Rio de Janeiro: Objetiva, 2001.

LEITE DE VASCONCELOS, José. Opúsculo. Onomatologia. Vol.III. Coimbra: Imprensa da Universidade, 1931.

MORI, Olga. Aspectos teóricos relevantes de las designaciones urbanas. In; Actes du XXV Congrès International de Linguistique e de Fhilologie Romanes. Innsbruck, 3-8, septembre, 2007.

SALAZAR-QUIJADA, Adolfo. La Toponimia en Venezuela. Caracas: Universidad

Central de Venezuela, Faculdad de Ciencias Economicas y Sociales, 1985.

SAMPAIO, Teodoro. 0 tupi na geografia nacional. 5.ed. São Paulo: Editora Nacional; Brasília, DF:INL,1987.

SARTORI. Tríssia Ordovás. Ruas de minha cidade - um estudo hodonímico. 2010. 82 f. (Dissertação de Mestrado). Programa de Pós-Graduação em Letras, Cultura e Regionalidade da Universidade de Caxias do Sul, Caxias do Sul, 2010.

SQUINELO, Ana Paula. A Guerra do Paraguai ontem e hoje - Mato Grosso e Mato Grosso do Sul (1868 - 2003). Edit 